\title{
REVIEW \\ Nutritional management of children with cerebral palsy
}

$\mathrm{KL} \mathrm{Bell}^{1,2}$ and L Samson-Fang ${ }^{3}$

Children with severe cerebral palsy and particularly those with oropharyngeal dysfunction are at risk of poor nutritional status. Determining the need and the mode of nutritional intervention is multifactorial and requires multiple methodologies. First-line treatment typically involves oral nutritional support for those children who are safe to consume an oral diet. Enteral tube feeding may need to be considered in children with undernutrition where poor weight gain continues despite oral nutritional support, or in those with oropharyngeal dysphagia and an unsafe swallow. Estimates for energy and protein requirements provide a starting point only, and ongoing assessment and monitoring is essential to ensure nutritional needs are being met, that complications are adequately managed and to avoid over or under feeding.

European Journal of Clinical Nutrition (2013) 67, S13-S16; doi:10.1038/ejcn.2013.225

Keywords: cerebral palsy; children; nutritional requirements; dietary intake; nutrition assessment

\section{INTRODUCTION}

Many children with cerebral palsy (CP) are at risk of poor nutritional status, particularly those with severe gross motor impairment and oropharyngeal dysfunction. ${ }^{1-3}$ Determining the need for nutrition intervention in children with $\mathrm{CP}$ requires the use of multiple methodologies. ${ }^{4,5}$ Indicators may include the following: ${ }^{2,6}$

- Plateaus in weight gain or growth resulting in deviation from an established 'pattern'.

- Evidence of low body-fat stores in combination with low weight in respect to height or length.

- Prolonged or stressful oral feeding or signs of pulmonary aspiration, or dehydration.

- Evidence of micronutrient deficiencies.

\section{ESTIMATING NUTRITIONAL REQUIREMENTS}

Before commencing any nutritional intervention, nutritional requirements must be established. Estimating the nutritional needs for a child with neurological impairment is not straightforward. Various methods have been proposed all of which are limited by the numerous assumptions. ${ }^{7-10}$ Accurate estimations are difficult because of variations in energy requirements related to the heterogeneity of the group, altered body composition and reduced physical activity levels. There is currently no commonly accepted method for estimating the energy needs of children and adolescents with $\mathrm{CP}$.

What is evident is that many children and adolescents with $C P$ have decreased energy requirements in comparison with typically developing groups and that these differences increase with increasing severity of gross motor impairment. ${ }^{8,11-13}$ Differences are partly because of decreased basal metabolic rate (related to reduced lean body mass and adaptation to chronic poor nutrition) but largely because of reductions in physical activity levels. ${ }^{13,14}$ Energy requirements of children and adolescents with severe
$\mathrm{CP}$ who utilise a wheelchair for mobility have been reported to be between 60 and $70 \%$ of those of healthy typically developing children. ${ }^{11,13,15}$ Participation in physical activity, including intense rehabilitation, may increase the energy requirements of children with $\mathrm{CP}$ and needs to be considered when estimating energy needs.

Adequate protein intake is essential to build and repair tissue, for adequate growth and development in childhood and adolescence and to promote lean tissue gain. There is currently no evidence to suggest that protein requirements of children and adolescents with CP differ to those of typically developing populations, and therefore recommendations for typically developing children and adolescents can be applied. For severely undernourished children with $\mathrm{CP}$, additional protein and energy may be required to promote 'catch up' growth. Overall, an intake of $2.0 \mathrm{~g} / \mathrm{kg}$ per day of protein and an additional 20\% increase in energy intake should be sufficient in these instances. ${ }^{16}$ Estimates for energy and protein requirements provide a starting point only, and ongoing assessment and monitoring is essential to avoid over or under feeding. Because of the difficulties with estimating nutritional requirements and often inaccurate reporting of dietary intake, ongoing assessment of whether a child is meeting his or her energy and protein needs should be determined through adequacy of weight gain and improvements in objective measures of nutritional status, and not solely based on reports of dietary intake.

In the absence of specific recommendations for use in individuals with $\mathrm{CP}$, standard recommendations for dietary intakes of vitamins, minerals and trace elements should be utilised. Inadequate dietary intakes may be addressed through the inclusion of foods rich in the micronutrient at risk or through supplementation. ${ }^{17}$ Correction of a diagnosed micronutrient deficiency (through blood and/or serum concentrations) is likely to require additional supplementation.

'Queensland Cerebral Palsy and Rehabilitation Research Centre, Children's Nutrition Research Centre, Queensland Children's Medical Research Institute, The University of Queensland, Brisbane, Queensland, Australia; ${ }^{2}$ Department of Paediatric Rehabilitation, Children's Health Queensland Hospital and Health Service, Herston, Brisbane, Queensland, Australia and ${ }^{3}$ Department of Pediatrics, University of Utah School of Medicine, Salt Lake City, UT, USA. Correspondence: Dr KL Bell, Queensland Cerebral Palsy and Rehabilitation Research Centre, Level 7, Block 6, Royal Brisbane and Women's Hospital, Herston 4029, Brisbane, Queensland, Australia.

E-mail: k.bell@uq.edu.au

This supplement was derived from a meeting with experts facilitated by Josephine Garvey and Annemiek Goedhart, held in Orlando in 2012. 


\section{NUTRITION SUPPORT}

The mode of administration of nutritional support will depend upon the nutritional status of the child, the child's ability to consume adequate quantities of food and fluids orally, and the risk of pulmonary aspiration. Where possible, first-line treatment will involve oral nutritional support including adequate positioning and physical support during mealtimes. Many children with CP have their own customised seating but may require additional body and head support to keep them stable and comfortable, and to ensure they swallow safely. The use of adaptive feeding equipment, including easy-to-hold cutlery and non-slip matting, may encourage independence by assisting children to self feed. Textures of food and thickness of fluids may need to be modified, under the guidance of a specialised feeding therapist, to ensure airway safety, maximise eating efficiency and reduce fatigue during mealtimes. Smaller more frequent meals can also be beneficial.

Because of the higher energy density of fat per gram $(37 \mathrm{~kJ}$ or $9 \mathrm{kcal} / \mathrm{g})$ compared with protein and carbohydrate $(17 \mathrm{~kJ}$ or $4 \mathrm{kcal} / \mathrm{g}$ ), the addition of extra fats to the diet can significantly increase the energy intake of a child without increasing the volume of food consumed using products typically found in the home. Fats and oils may be added during cooking or to the child's meal upon serving. High fat spreads can be used including nut spreads or avocado. Milk drinks can be fortified using dry milk powders, cream and/or ice cream as well as flavourings to boost energy and protein density. Protein intake can be further improved by including protein containing foods at all meals, such as soft diced or puree meats, dairy products, eggs, lentils and legumes.

If no improvement in nutritional status is seen after a suitable time period, supplementation with commercially available oral supplements and/or indications for enteral tube feeding should be considered. Commercially available modular products (for example, carbohydrate polymers, protein powders, combined carbohydrate and fat supplements) may be added to foods and fluids to increase energy/protein density. However, micronutrient provision should also be considered. Numerous oral nutritional supplements (sip feeds) are available commercially including milkor juice-based products for both pediatric and adult populations. There are formulas of higher energy density and (or) with added fibre depending on the needs of the child. Sip feeds have the benefit of significantly contributing to micronutrient intake (and potentially fibre intake) as well as providing additional energy and protein. Feeds suitable for the individual's age should be selected and formulas may, or may not be, nutritionally complete. When fortifying foods with protein powders or dry milk powders or when including sip feeds, it is important to consider the child's total intake of nutrients and ensure recommendations for upper limits are not exceeded. ${ }^{18}$

The appropriate length of time for a trial of oral nutritional support will vary depending on the age of the child and the degree to which their nutritional status is compromised. Initial follow-up in 1-3 months is usually sufficient; however, younger children, such as infants and those with a (very) poor nutritional status, will need to be reviewed more frequently. ${ }^{19}$ If, despite oral nutritional support, weight gain continues to be inadequate, enteral tube feeding may need to be considered.

Enteral tube feeding is indicated in children with CP with a functional gastrointestinal tract who are unable to meet their nutritional requirements orally, despite oral nutritional support; those with severe undernutrition; and those with significant feeding and swallowing dysfunction (resulting in risk of pulmonary aspiration or prolonged and stressful oral feeding). ${ }^{19,20}$ It may be used as the sole source of nutrition for children with an unsafe swallow, or to supplement oral intake in those children safe to consume some food and/or fluids orally. ${ }^{21}$
The decision to commence tube feeding is complex for families and carers of children with $\mathrm{CP}$ and may be filled with decisional conflict. $^{22,23}$ The values and meanings of feeding and eating are much more complex than simply providing adequate nutrition and maintaining weight gain. ${ }^{23} \mathrm{~A}$ balanced and sensitive approach to informing parents and carers regarding the risks and benefits of enteral tube feeding and exploration into how tube feeding will fit into the context of everyday life is essential to assist in the decision-making process. ${ }^{22}$

The choice of access for enteral tube feeding will depend upon the anticipated duration of feeding and the clinical status of the child. ${ }^{24}$ Nasogastric tubes are suitable for short-term use, as they are relatively less invasive. Nasogastric feeding may be utilised before gastrostomy insertion to allow for nutritional rehabilitation before surgery and as a 'trial run' to assess tolerance and efficacy of enteral tube feeding. ${ }^{6}$ Long-term use is not recommended as the tubes are easily dislodged, blockages can occur and they may cause nasopharyngeal discomfort and irritation. ${ }^{25}$ For long-term feeding, gastrostomy is the preferred route because of improved comfort and reduced need for frequent tube changes. In children with neurological disabilities, both nasogastric and gastrostomy feeds have been shown to improve nutritional status.

Post-pyloric feeding (nasojejunal, gastrojejunostomy and jejunostomy) may be indicated in children with $\mathrm{CP}$ with severe gastroesophageal reflux and vomiting resulting in growth faltering and in those at increased risk of aspiration. ${ }^{24}$ Its use, however, is limited by the high frequency of complications and tube replacements. ${ }^{26}$ Gastric feeding remains the preferred route when possible as it is more physiological, tube insertion is easier and bolus feeds may be utilised. ${ }^{25}$

\section{ENTERAL TUBE-FEEDING REGIMENS}

Enteral tube-feeding regimens must be tailored to the individual child's needs and will be influenced by the route of access (that is, gastric versus post pyloric), tolerance of feeds, contribution of oral intake and family routine and lifestyle. Continuous feeding regimens are often recommended in children with poor feed tolerance. ${ }^{6}$ Post-pyloric feeds must be delivered continuously to prevent diarrhoea and dumping syndrome. ${ }^{25} \mathrm{~A}$ period of time off feeds during the day can be managed for many children requiring continuous infusions allowing for daily activities such as bathing, transport, and so on. Bolus feeding can provide greater opportunity for oral intake and may be more suitable to the lifestyles of many families. The timing of bolus feeds is important to provide adequate opportunity for the development of hunger before oral meals. A combination of overnight continuous feeds with boluses during the day may be required to provide sufficient nutrition for the child.

\section{FORMULA SELECTION}

There are many varieties of commercial enteral feeds available including polymeric, semi-elemental and elemental formulations, tailored for different age groups based on the changing nutritional requirements throughout the lifespan. Most enteral feeds are designed to provide complete nutrition, that is, to serve as the sole source of nutrition by meeting all essential nutrient requirements. ${ }^{25}$ The initial feed of choice is usually a standard energy density $(1.0 \mathrm{kcal} / \mathrm{ml}(4.2 \mathrm{~kJ} / \mathrm{ml}))$ polymeric feed suitable for the age of the child. For those children with an increased energy requirement or poor tolerance of large volumes of feed, a highenergy density formula may be useful (for example, $1.5 \mathrm{kcal} / \mathrm{ml}$ $(6.3 \mathrm{~kJ} / \mathrm{ml}))$. For children with lower energy needs, such as those that gain weight too rapidly, a lower-energy density formula can be used $(0.75 \mathrm{kcal} / \mathrm{ml}(3.15 \mathrm{~kJ} / \mathrm{ml})) .{ }^{15}$ Feeds with dietary fibre have potential beneficial effects for the prevention of both diarrhoea and constipation. ${ }^{27}$ Whey-based formulas may be beneficial in 
children with poor feed tolerance because of delayed gastric emptying. $^{28}$

\section{HOME-PREPARED FORMULATIONS}

Pureed food given via gastrostomy has been suggested to reduce gagging and retching in children following fundoplication surgery; ${ }^{26}$ however, there is insufficient evidence to support this claim. Concerns regarding the nutritional adequacy and safety of home-prepared tube feeds have been reported. ${ }^{26}$ Even with the involvement of a dietician, poor weight gain of children receiving them has been reported. ${ }^{26}$

\section{FEED SAFETY}

Microbiological contamination of enteral tube feeds can occur even with the use of commercial formulas. ${ }^{29}$ Risk factors include the environment and manner in which the feed is prepared, poor attention to hygiene during handling, repeated topping up of the feed container and increasing feed-hanging times. ${ }^{25}$ Commercially available 'ready to hang' closed enteral feeding systems are designed to limit handling procedures with the introduction of the giving set spike into the pack.

\section{FOLLOW-UP AND MONITORING}

The effectiveness of any nutrition intervention must be determined through regular nutrition monitoring. Monitoring may involve measures of actual nutrient delivery (for example, energy, protein and micronutrients) and comparison with measured or estimated needs. ${ }^{19}$ In children with $\mathrm{CP}$, estimated needs are a starting point only. A more sensitive indicator that the child is receiving enough dietary energy (and protein) is adequacy of weight gain. Generally speaking, follow-up and monitoring of nutrition interventions will involve ensuring the child's nutritional status is adequate or improving, management of difficulties with feed tolerance, ensuring safety of feeds and nutrient intake, balancing enteral tube feeding with oral intake and working towards weaning off tube feeding where appropriate. ${ }^{19}$

The frequency of nutritional monitoring depends upon the severity of the child's clinical condition, age, nutritional status and existing nutrient deficiencies. ${ }^{19}$ Once a child is established on nutrition support and weight gain is occurring at desired rates, follow-up in 6-12 months has been suggested. ${ }^{30}$

\section{MANAGEMENT OF COMPLICATIONS}

Common complications related to enteral tube feeding in children with CP may include constipation, vomiting or regurgitation, diarrhea, or excess weight gain. To treat constipation, ensure that the child's dietary intake of fibre and fluids is adequate. The use of fibre-containing feeds (tube or sip feeds) or fibre supplements may be helpful; however, medications may continue to be required. ${ }^{27}$

For children with vomiting or regurgitation, first ensure that the feeding tube is correctly placed. Consider reducing the infusion rate, using smaller more frequent bolus feeds and/or positioning the child upright during feeds. ${ }^{25}$ If poor feed tolerance continues, inadequate, enteral tube then post-pyloric feeding may be helpful. ${ }^{24}$ Medical treatment for gastroesophageal reflux disease may be required and surgical treatment may need to be considered. ${ }^{25}$

Management of diarrhea may initially involve slowing the feed infusion rate, reducing bolus size or changing to continuous feeds, and/or changing to a feed with a lower osmolarity. ${ }^{25}$ Infusion rates, bolus size and strength of formula can be increased gradually as tolerated. Diarrhea may occur in children with impaired gut function, in which case a change to a semi-elemental formula may be indicated. Diarrhea may also be caused by microbial contamination. In this case, sterile, commercially produced feeds should be used when possible, with appropriate feed hang times, and high levels of hygiene should be ensured when preparing and delivering feeds. ${ }^{25}$

Excess weight gain can occur when the child's energy intake is exceeding his or her actual energy requirement. In this instance, the energy intake of the child should be reduced by reducing feed volume, using a formula that is nutritionally complete in a smaller volume, or by using a feed of lower energy density (for example $0.75 \mathrm{kcal} / \mathrm{ml}(3.15 \mathrm{~kJ} / \mathrm{ml})){ }^{15}$

Recommended intakes for protein and micronutrients can be difficult to meet in children with very low energy requirements while preventing excess weight gain. ${ }^{15}$ Additional protein and/or micronutrient supplementation may be required. If supplementation is deemed necessary, it is important to ensure that safe upper limits for nutrients are not exceeded. ${ }^{18,31}$

This supplement is provided as a professional service by the Paediatric Division of Nutricia Advanced Medical Nutrition.

\section{CONFLICT OF INTEREST}

KLB and LSF have received lecture fees from Danone. Spouse of LSF is investor and Chief Scientific Officer of Veritract (specialized feeding tube). KLB has received grant support from the national Health and Medical Research Council (NHMRC 569605), Australia.

\section{REFERENCES}

1 Brooks J, Day S, Shavelle R, Strauss D. Low weight, morbidity, and mortality in children with cerebral palsy: new clinical growth charts. Pediatr 2011; 128: e299-e307.

2 Kuperminc M, Stevenson RD. Growth and nutrition disorders in children with cerebral palsy. Dev Dis Res Rev 2008; 14: 137-146.

3 Fung EB, Samson-Fang L, Stallings VA, Conaway M, Liptak G, Henderson RC et al. Feeding dysfunction is associated with poor growth and health status in children with cerebral palsy. J Am Diet Assoc 2002; 102: 361-373.

4 Arvedson JC. Feeding children with cerebral palsy and swallowing difficulties. Eur J Clin Nutr 2013; 67: S9-S12.

5 Samson-Fang L, Bell KL. Assessment of growth and nutrition in children with cerebal palsy. Eur J Clin Nutr 2013; 67: S5-S8.

6 Marchand V, Motil KJ. NASPGHAN Committee on Nutrition. Nutrition Support for Neurologically Impaired Children: A Clinical Report of the North American Society for Pediatric Gastroenterology, Hepatology, and Nutrition. J Pediatr Gastroenterol Nutr 2006; 43: 123-135.

7 Krick J, Murphy PE, Markham JF, Shapiro BK. A proposed formula for calculating energy needs of children with cerebral palsy. Dev Med Child Neurol 1992; 34: 481-487.

8 Rieken R, van Goudoever JB, Schierbeek H, Willemsen SP, Calis EAC, Tibboel $\mathrm{D}$ et al. Measuring body composition and energy expenditure in children with severe neurologic impairment and intellectual disability. Am J Clin Nutr 2011; 94: 759-766.

9 Bell K, Owens J. Cerebral palsy. In: Stewart R (ed.) Paediatric Nutrition and Dietetics. Campbell House: Brisbane, Australia, 2012.

10 Azcue MP, Zello GA, Levy LD, Pencharz PB. Energy expenditure and body composition in children with spastic quadriplegic cerebral palsy. J Pediatr 1996; 129: $870-876$

11 Walker JL, Bell KL, Boyd RN, Davies PS. Energy requirements in preschool-age children with cerebral palsy. Am J Clin Nutr 2012; 96: 1309-1315.

12 Bell KL, Davies PSW. Energy expenditure and physical activity of ambulatory children with cerebral palsy and of typically developing children. Am J Clin Nutr 2010; 92: 313-319.

13 Stallings VA, Zemel BS, Davies JC, Cronk CE, Charney EB. Energy expenditure of children and adolescents with severe disabilities: a cerebral palsy model. Am J Clin Nutr 1996; 64: 627-634.

14 Bandini LG, Schoeller DA, Fukagawa NK, Wykes LJ, Dietz WH. Body composition and energy expenditure in adolescents with cerebral palsy or myelodysplasia. Pediatr Res 1991; 29: 70-77.

15 Vernon-Roberts A, Wells J, Grant H, Alder N, Vadamalayan B, Eltumi M et al. Gastrostomy feeding in cerebral palsy: enough and no more. Dev Med Child Neurol 2010; 52: 1099-1105.

16 Pencharz PB. Protein and energy requiements for 'optimal' catch-up growth. Eur J Clin Nutr 2010; 64: S5-S7. 
17 Hillesund E, Skranes J, Trygg K, Bohmer T. Micronutrient status in children with cerebral palsy. Acta Paediatra 2007; 96: 1195-1198.

18 WHO/FAO/UNU Expert Committee. Protein and Amino Acid Requirements in Human NutritionGeneva, Switzerland, 2007.

19 ASPEN Board of Directors the Clinical Guidelines Task Force. Guidelines for the use of parenteral and enteral nutrition in adult and pediatric patients. $J$ Parenter Enteral Nutr 2002; 26(1 Suppl): 1SA-138SA (Erratum in J Parenter Enteral Nutr 2002; 26: 144).

20 Sullivan PB, Juszczac E, Bachlet A, Lambert B, Vernon-Roberts A, Grant $\mathrm{H}$ et al. Gastrostomy tube feeding in cerebral palsy: a prospective, longitudinal study. Dev Med Child Neurol 2005; 47: 77-85.

21 Arrowsmith F, Allen J, Gaskin K, Somerville H, Clarke S, O'Loughlin E. The effect of gastrostomy tube feeding on body protein and bone mineralization in children with quadriplegic cerebral palsy. Dev Med Child Neurol 2010; 52: 1043-1047.

22 Craig GM, Scambler G, Spitz L. Why parents of children with neurodevelopmental disabilities requiring gastrostomy feeding need more support. Dev Med Child Neurol 2003; 45: 183-188.

23 Mahant S, Jovcevska V, Cohen E. Decision-making around gastrostomy-feeding in children with neurologic disabilities. Pediatrics 2011; 127: e1471-e1481.

24 Gottrand F, Sullivan PB. Gastrostomy tube feeding: when to start, what to feed and how to stop. Eur J Clin Nutr 2010; 64(Suppl 1): S17-S21.
25 ESPGHAN Committee on Nutrition. Practical approach to paediatric enteral nutrition: a comment by the ESPGHAN committee on nutrition. J Pediatr Gastroenterol 2010; 51: 110-122.

26 Pentiuk S, O'Flaherty T, Santoro K, Willging P, Kaul A. Pureed by gastrostomy tube diet improves gagging and retching in children with fundoplication. J Parenter Enter Nutr 2011; 35: 375-379.

27 Elia M, Engfer MB, Green CJ, Silk DBA. Systematic review and meta-analysis: the clinical and physiological effects of fibre-containing enteral formulae. Aliment Pharmacol Ther 2008; 27: 120-145.

28 Brun AC, Stordal K, Johannesdottir GB, Bentsen BS, Medhus AW. The effect of protein composition in liquid meals on gastric emptying rate in children with cerebral palsy. Clin Nutr 2012; 31: 108-112.

29 Patchell C, Anderton A, MacDonald A. Bacterial contamination of enteral feeds Arch Dis Child 1994; 70: 327-330.

30 Mascarenhas MR, Meyers R, Konek S. Outpatient nutrition management of the neurologically impaired child. Nutr Clin Pract 2009; 23: 597-607.

31 WHO/FAO/UNU Expert Committee. Vitamin and Mineral Requirements in Human Nutrition Geneva, Switzerland, 2004.

This work is licensed under a Creative Commons Attribution 3.0 Unported License. To view a copy of this license, visit http:// creativecommons.org/licenses/by/3.0/ 